HEALING ARTS: MATERIA MEDICA

\title{
A Young Woman and Her Withered Rose: Humanizing the Opioid Epidemic
}

\section{Jason L. Campbell, MD, MS}

Department of Anesthesiology \& Perioperative Medicine, Oregon Health \& Science University, Portland, OR, USA.

$\mathrm{I}$ walked into the room.

A frail young woman was angled in her hospital bed resting peacefully. A vibrant rose tattoo adorned her left ankle and blonde strands of hair covered her eyes. Although I closed the door as softly as I could, she abruptly awoke. Mildly unaware of her surroundings, she cautiously glanced at me-observing my white coat - unaware of her future. 'Hi, I'm Dr. Campbell, but please call me Jason. I'll be one of the doctors caring for you." She silently nodded in acknowledgment; her attention glued elsewhere as I approached her. I do not know if this is what I visualized in my head when I thought of an intravenous drug user. Most, if not all, of my previous thoughts revolved around a two-dimensional image of danger, dishevelment, and unpredictability.

The truth is never that simple.

In actuality, she may not make it to her 30th birthday, a fact worsened by her limited awareness of this fatal reality. Her chance of survival-lessened by an abnormal growth on one of the valves in her heart-is extremely low without a surgical intervention. One day during her physical examination, I noticed the sound of her heart murmur had augmented. And so, too, had my understanding of her life story. She told me that at the age of ten, she was kidnapped, abandoned, and left on the streets to fend for herself with only the clothes on her back, minimal food, and the shelter of downtown businesses. By the time her grandparents had found her, she had already endured so much pain for which there was no delete key. Still to this day, I do not know if she was actually abducted, recognizing this may or may not be true-nevertheless it was her truth. For health care providers, these narratives can give us views, albeit cloudy ones, into a patient's understanding of how their life has influenced their disease. We as physicians must have a passion for people and a comprehension of the many ways in which lived experience is expressed.

Every few days - when my scheduled allowed-I would return to her room. She spoke, I listened. It was human. "Four months - I was clean. It was the hardest thing I've ever done, Dr. Campbell. I got a kidney stone, was prescribed opioid medications and relapsed. They don't know what I went through to stay clean. All they see is a junkie lying in this bed. That's all I am to them!"

The more she spoke, the more the same questions circulated through my mind. How had she arrived at this point? Did we, the physicians, do this?
According to the National Institute on Drug Abuse (NIDA), for new patients prescribed opioids for greater than 30 days in the first year, $47 \%$ continue to do so for greater than 3 years ${ }^{1}$. Approximately, 4-6\% who misuse prescription opioids transition to heroin and $80 \%$ of people who use heroin misused prescription opioids first ${ }^{1}$.

Statistics afford us an ability to comprehend the overarching picture and those same statistics allow us to detach ourselves from the realization that each percentage point represents individual patients with their own story.

In 2012, health care providers wrote 259 million prescriptions for opioid pain medication which equated to enough for every adult in the USA to have a bottle of pills ${ }^{2}$. As in the case of my patient, addiction treatment need in a community often far exceeds the capacity to provide counseling or medication-assisted therapy like buprenorphine or methadone ${ }^{3}$. The Center for Disease Control, recognizing this health crisis plaguing patients and society, has created guidelines for outpatient opioid prescribing practice, where many of the opioid issues have arisen (IV). Furthermore, experts agree that clinicians prescribing opioids should identify treatment resources for opioid use disorder in the community and work fervently together to ensure sufficient treatment capacity for opioid use disorder at the practice level ${ }^{4}$.

As I prepared to leave, she asked me, "What would you do if you could have all of your pain go away?"

I returned a grin, timid in nature, ignorant, unable to contrive a purposeful and succinct answer. I struggle with the fact that I had, like other medical providers, certain prejudices and assumptions regarding the opioid crisis and the individuals plagued by this calamity. Science can teach us the pathophysiology of addiction and the pharmacology of the appropriate medications for safe opioid withdrawal, but it is only through our patients that we can begin to understand the complexity and hardships many in the opioid epidemic face daily.

As she continued to improve, one day prior to discharge she said, "When you first met me, you thought I was going to die, didn't you?" a smile dawning on her face.

"I'll see you tomorrow."

I returned the smile.

J Gen Intern Med 35(2):590-1

DOI: $10.1007 / \mathrm{s} 11606-019-05332-9$

(c) Society of General Internal Medicine 2019

Published online October 19, 2019 
Corresponding Author: Jason L. Campbell, MD, MS; Department of Anesthesiology \& Perioperative Medicine Oregon Health \& Science University, 3181 Sam Jackson Park Rd, Portland, OR 97239, USA (e-mail: campbjas@ohsu.edu).

\section{REFERENCES}

1. National Institute on Drug Abuse. "Opioid Overdose Crisis.” NIDA. 2019. www.drugabuse.gov/drugs-abuse/opioids/opioid-overdose-crisis\#seven. $8 / 12 / 2019$

2. Vowles KE, McEntee ML, Julnes PS, Frohe T, Ney JP, van der Goes DN. Rates of opioid misuse, abuse, and addiction in chronic pain: a systematic review and data synthesis. Pain. 2015;156(4):569-576. https://doi.org/ 10.1097/01.j.pain.0000460357.01998.f1.

3. Jones CM, Campopiano M, Baldwin G, McCance-Katz E. National and state treatment need and capacity for opioid agonist medication-assisted treatment. Am J Public Health. 2015; 105:e55-63.

4. Dowell D, Haegerich TM, Chou R. CDC Guideline for Prescribing Opioids for Chronic Pain - United States, 2016. MMWR Recomm Rep. 2016;65(RR1):1-49. https://doi.org/10.15585/mmwr.rr650lelexternal-icon

Publisher's Note Springer Nature remains neutral with regard to jurisdictional claims in published maps and institutional affiliations. 